\title{
Unusual Complication of Ventriculoperitoneal Shunt: Anal Extrusion
}

\author{
Lt Col R Handa (Retd) ${ }^{*}$, Col R Kale ${ }^{+}$, Lt Col MM Harjai ${ }^{\#}$
}

MJAFI 2007; 63 : 82-84

Key Words : Hydrocephalus; Shunt malfunction; Anal extrusion

\section{Introduction}

$\mathrm{T}_{\mathrm{h}}^{\mathrm{h}}$ he diversion of cerebrospinal fluid (CSF) for hydrocephalus is an established surgical practice, after its feasibility was demonstrated in the early 1900s [1]. Various valve assemblies have been devised and we use valve regulated ventriculoperitoneal shunt with a slit lower end [2]. More than 100 shunts have been placed for congenital/post meningitis hydrocephalus in children, at our centre. Many abdominal complications have been described which include fibrous encasement of the peritoneal tip, blocking or kinking of the distal tube, slipping out through the surgical wound or migration of the shunt or its component parts into the various abdominal cavities [2]. Other complications are infection, CSF fistula, paralytic ileus in the immediate postoperative period, failure of peritoneal absorption of the diverted CSF, perforation of the bowel by the abdominal tube, development of hydrocele, appearance of a peritoneal cyst and spontaneous extrusion of the tube through the umbilicus $[3,4]$. We highlight an unusual complication of this procedure with two of our cases developing spontaneous extrusion of the lower end of the tube through the anal opening. The possible predisposing factors for this complication are discussed.

\section{Case Report}

Case 1: An eighteen month old girl with post meningitic hydrocephalus had undergone a right ventriculo-peritoneal shunt in January 2002. She was on antitubercular therapy for tubercular meningitis. In May 2002 she presented with a two day history of high fever, an episode of convulsion, deterioration of neurological status and protrusion of the shunt catheter per anum (Fig. 1). The patient had neck rigidity and gaze paralysis. CSF studies showed frank infection. The patient was taken up for immediate surgery, an incision was made in the neck and the complete shunt assembly was taken out. The patient was put on antibiotics, anticonvulsant and

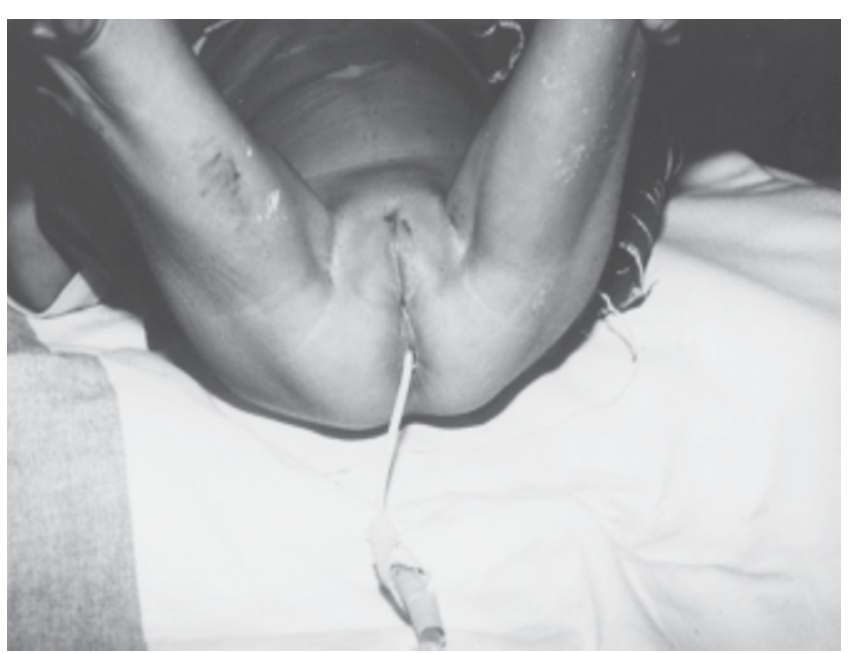

Fig. 1 : Peritoneal end of Chabbra® ventriculoperitoneal shunt protruding from anus connected to a urobag

decompressive measures with diamox and glycerol. She made good recovery and ventricular tap after two weeks showed clearing of infection. A fresh ventriculo-peritoneal shunt was placed on the left side with an uneventful postoperative period.

Case 2: A five year old boy with congenital hydrocephalus underwent the initial ventriculo-peritoneal shunt in December 2000. Post operatively the patient developed a pelvic abscess, which was drained. He presented in December 2003 with one day history of shunt catheter extrusion per anum (Fig. 2). At that time there were no signs or symptoms to suggest evidence of infection and shunt tap from shunt chamber showed CSF to be clear with normal cytology. The ventriculoperitoneal shunt was revised the same day by change of the lower end of the shunt through the neck incision. The patient again developed catheter extrusion per anum 48 hours later. Since the child had been under observation for more than 72 hours and there was no clinical, biochemical or bacteriological evidence of meningitis, revision of the lower end of the shunt was performed. Postoperatively, the patient developed meningitis and the shunt was removed. He was managed

"Ex-Classified Specialist (Surgery \& Paediatric Surgery),Command Hospital (EC) Kolkata - 700027. ${ }^{+}$Senior Advisor (Surgery and Paediatric Surgery), ${ }^{\# C}$ lassified Specialist (Surgery \& Paediatric Surgery), Army Hospital (Research and Referral), New Delhi - 110010.

Received : 05.02.2005; Accepted : 01.06.2006 


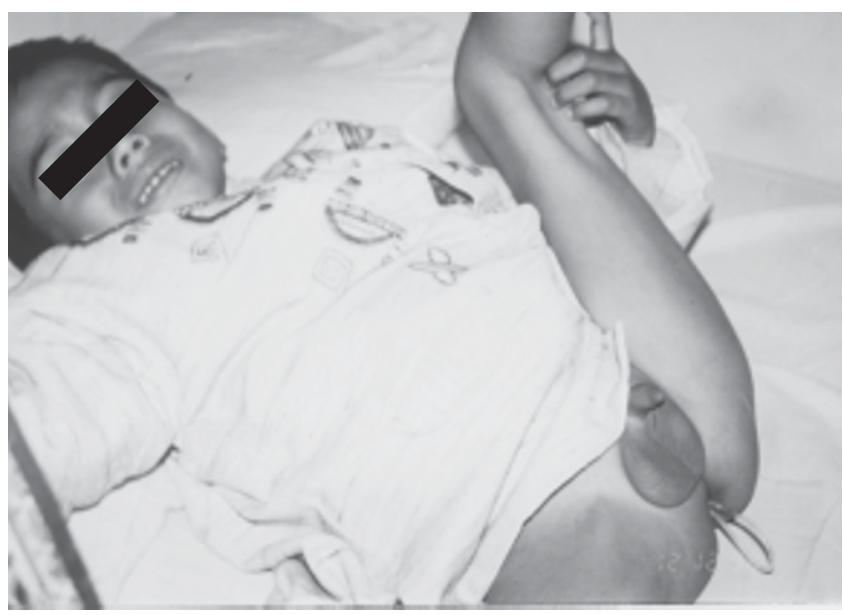

Fig. 2 : Photograph showing protruding peritoneal end of Chabbra ${ }^{\circledR}$ ventriculoperitoneal shunt through anus in a boy

with antibiotics and decompressive agents. After a month, a burr hole ventricular tap revealed clear sterile CSF and the ventriculo peritoneal shunt was placed. However the child again developed low grade meningitis and the shunt was exteriorized. It took another month for the CSF to clear up. At this stage the complete exteriorized shunt assembly was removed and a fresh shunt placed on the contralateral side in Mar 2004.

\section{Discussion}

The ideal system for CSF diversion has not been devised. Ventriculo peritoneal shunt, which diverts the CSF from an obstructed ventricular cavity to the peritoneal cavity for fluid absorption, is common in the paediatric age group. Many complications have been reported with this method. The abdominal complications include shunt malfunction, infection, CSF loculation and cyst formation, migration of the shunt within the peritoneal cavity to an area of non absorption or outside the peritoneal cavity, perforation of a viscera or bowel obstruction secondary to adhesions [1,5]. Shunt tubing migration to thorax causing pleural effusion through the umbilicus and to the hernial sac has been also described $[1,4]$. Viscera perforation by the shunt catheter including bowel, urinary bladder, uterus, vagina, rectum or gall bladder is known. Isolated case reports of spontaneous protrusion of the peritoneal end of ventriculo peritoneal shunts through the anus have also been reported in literature [6-8], but management of these cases is difficult. The possible predisposing factors are weak bowel musculature in myelomeningocele, use of stiff peritoneal catheters and local infective adhesions [7].

The mechanism of anal extrusion is uncertain and it possibly occurs when a long tubing is left in the abdominal cavity. The perforation of the bowel lumen occurs when the freely moving catheter gets adherent to the serosa of a viscus and the bevelled end of the tube, coupled with the continuous water hammer effect

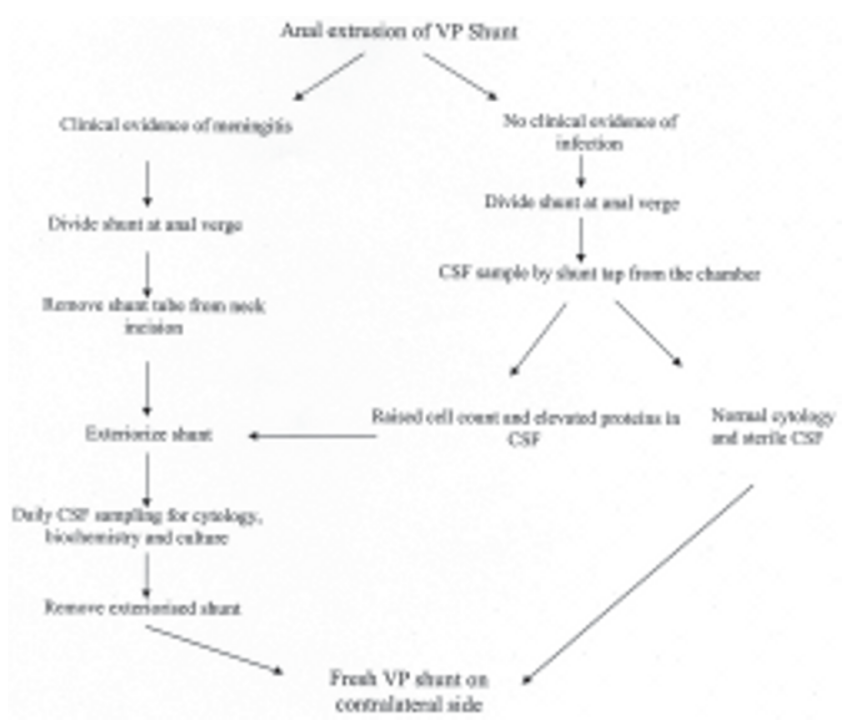

Fig. 3 : Algorithm outlining the management of an anal protrusion of the ventriculoperitoneal shunt

of the cerebrospinal fluid pulsations, penetrate the walls and eventually perforate the viscus. Thereafter the peristaltic waves drive the 'foreign body' forward. There are no abnormal abdominal signs or symptoms and anal extrusion of the shunt tubing presents without any preceding abdominal symptomatology. Our second case presented in this manner. The first case presented with meningitis which was possibly an ascending infection after the bowel perforation by the shunt tubing.

The management of these cases involves shunt removal/exteriorization, control of infection and reinsertion of shunt at an appropriate time. In the first case, the shunt was removed, adequate control over CSF production was achieved and re-shunting was done after infection control. In anal extrusion, slight traction should be applied on the shunt tubing to divide it as high as possible at the anal verge and the remaining shunt tube should be removed in a retrograde fashion from a neck incision. Spillage of bowel contents into the peritoneal cavity resulting in peritonitis does not occur following the removal of the shunt tubing due to the formation of a fibrous tract around the catheter which is attached to the bowel surface. Exteriorisation of a shunt is required, especially in children to prevent development of peritonitis due to the infected CSF. Exteriorization is also essential in children, rather than removal, because CSF production cannot be controlled easily and even small changes in intracranial pressure can result in dramatic manifestations. The protocol for management of an anal extrusion of a ventriculoperitoneal shunt is depicted as an algorithm (Fig. 3).

Sometimes, removal of the shunt tubing does not occur smoothly and knotting of a long shunt tube or twisting of the tube amongst the bowel loops requires laparotomy. 
Alternatively, laparoscopy can be of assistance in visualization of the shunt tubing and its disengagement. Recently laparoscopic management of abdominal complications and endoscopic management of anal protrusion of ventriculo-peritoneal shunts have been reported in the literature $[9,10]$.

Anal extrusion of the ventriculoperitoneal shunt is an uncommon but well documented entity. Presentation may or may not be with associated meningitis. The authors recommend that it would be prudent to wait for sufficient period of time before shunt revision is undertaken in such cases, to ensure an uneventful recovery.

\section{Conflicts of Interest}

None identified

\section{References}

1. Agha F, Amendola MA, et al. Unusual abdominal complications of ventriculoperitoneal shunts. Radiology 1983; 146:323-6.

2. Ames RH. Ventriculo-peritoneal shunt:The management of hydrocephalus. J Neurosurg 1967; 27:525-9.

3. Adeloye A. Spontaneous extrusion of the abdominal tube through the umbilicus complicating peritoneal shunt for hydrocephalus. J Neurosurg 1973;38:758-60.

4. Wani AA, Ramzan A, Wani MA. Protrusion of a peritoneal catheter through the umbilicus: An unusual complication of a ventriculoperitoneal shunt. Pediatr Surg Int 2002; 18: 171-2.

5. Grosfeld JL, Cooney DR, Smith J. Intra-abdominal complications following ventriculo-peritoneal shunt procedures. Pediatrics 1974; 54:791-6.

6. Adeloye A. Protrusion of ventriculo peritoneal shunt through the anus: report of two cases. East Afr Med J 1997; 74: 337-9.

7. Miserocchi G, Sironi VA, Ravagnati L. Anal protrusion as a complication of ventriculo-peritoneal shunt. Case report and review of the literature. J Neurosurg Sci 1984; 28: 43-6.

8. Digray NC, Thappa DR, Arora M, Mengi Y, Goswamy HL. Silent bowel perforation and transanal prolapse of a ventriculoperitoneal shunt. Pediatr Surg Int 2000; 16: 94-5.

9. Esposito C, Porreca A, Gangemi M, Garipoli V, De Pasquale M. The use of laparoscopy in the diagnosis and treatment of abdominal complications of ventriculo-peritoneal shunts in children. Pediatr Surg Int 1998; 13: 352-4.

10. Sharma A, Pandey AK, Radhakrishnan M, Kumbhani D, Das HS, Desai N. Endoscopic management of anal protrusion of ventriculo-peritoneal shunt. Indian J Gastroenterol 2003; 22: 29-30.

\section{ATTENTIONADVERTISERS}

Rates of advertisements in Medical Journal Armed Forces India :

\begin{tabular}{|c|c|c|c|}
\hline & Black \& White & Colour & Size \\
\hline Full page (per issue) & Rs. 5000/- & Rs. 10000/- & $25 \times 18 \mathrm{cms}$ \\
\hline \multirow[t]{2}{*}{ Half page (per issue) } & Rs. 3000/- & Rs. 6000/- & $18 \times 12 \mathrm{cms}$ \\
\hline & \multicolumn{3}{|c|}{ (Positive for advertisement to be supplied by client) } \\
\hline \multirow[t]{4}{*}{ Inserts (two pages) } & \multicolumn{3}{|c|}{ Rs. 5000/- per insert (Black and White / Colour) } \\
\hline & \multicolumn{3}{|c|}{ (Printed inserts to be supplied by client) } \\
\hline & \multicolumn{3}{|c|}{ Address for Correspondence } \\
\hline & $\begin{array}{l}\text { EDITO } \\
\text { CAL JOURNAI } \\
\text { FORCES MED }\end{array}$ & $\begin{array}{l}\text { IEF } \\
\text { FORCES II } \\
\text { LLEGE, PUN }\end{array}$ & 040 \\
\hline
\end{tabular}

